\title{
THE CURRENT AND POTENTIAL ROLE OF SATELLITE REMOTE SENSING IN THE CAMPAIGN AGAINST MALARIA
}

\author{
Yaniv Kazansky \\ University of Maryland, United States of America, yaniv.kazansky@gmail.com \\ Danielle Wood, PhD \\ Johns Hopkins University, United States of America, dwood26@jhu.edu, 617-794-1760 \\ (Corresponding Author) \\ Jacob Sutherlun \\ Johns Hopkins University, United States of America, jacob.n.sutherlun@gmail.com
}

\begin{abstract}
:
Malaria and other vector borne diseases claim lives and cause illness, especially in less developed countries. Although well understood methods, such as spraying and insecticidal nets, are identified as effective deterrents to malaria transmission by mosquitos, the nations that have the greatest burden from the disease also struggle to deploy such measures sufficiently. More targeted and up to date information is needed to identify which regions of malariaendemic countries are most likely to be at risk of malaria in the near future. This will allow national governments, local officials and public health workers to deploy protective equipment and personnel where they are most needed. This paper explores the role of environmental data generated via satellite remote sensing as an ingredient to a Malaria Early Warning System. Data from remote sensing satellites can cover broad geographical areas frequently and consistently. Much of the relevant data may be accessed by malaria-endemic countries at minimal cost via international data sharing polices. While previous research studies have demonstrated the potential to assign malaria risk to a geographic region based on indicators from satellites and other sources, there is still a need to deploy such tools in a broader and more operational manner to inform decision making on malaria management. This paper describes current research on the use of satellite-based environmental data to predict malaria risk and examines the barriers and opportunities for implementing Malaria Early Warning Systems enabled by satellite remote sensing. A Systems Architecture framework analyses the components of a Malaria Early Warning System and highlights the need for effective coordination across public and private sector organizations.
\end{abstract}

\section{INTRODUCTION}

The World Health Organization (WHO) estimates that in 2013, there were 198 million malaria cases worldwide and 584,000 deaths (WHO 2014a). While recent efforts to diminish this threat have resulted in decreasing mortality rates, more work is needed to reduce transmission rates and the overall footprint of malaria. Malaria cases are predominately concentrated in sub-Saharan Africa, but there are still pockets of malaria on almost every continent (IAMAT 2014). Malaria disproportionately affects less developed countries (WHO 2014b); resources from multinational, national and non-governmental organizations have been employed to fight malaria in these countries, yet a child dies every minute from malaria in Africa (WHO 2014a). Public health officials and international agencies are constantly reacting to malaria events around the world. With limited resources, countries have to make tough choices based on partial information about where to deploy malaria prevention efforts and which types of interventions to employee. Increasing the use of satellite-based remote sensing data as one source of information can help reduce the uncertainty by providing key indicators to decision makers about malaria risk factors. The data from satellites contributes to risk models that help identify the geographic regions that are most likely to be impacted by vector borne disease in the near future. This paper explores the information that satellite remote sensing can provide and identifies a framework for the operation of a Malaria Early Warning System that is enabled by earth observation data coupled with other types of data.

Page 1 of 17

(C) 2015. This manuscript version is made available under the Elsevier user license http://www.elsevier.com/open-access/userlicense/1.0/ 
Humans may become infected with malaria when they are bitten by female Anopheles mosquitos that carry the malaria parasite from host to host. Four species of malaria parasites with the capability to infect people occur with different frequencies around the world, but one species (Plasmodium falciparum) stands out as being the most common and the most likely to cause death. The other parasites are P. viva, P. malariae and P. ovale (WHO 2007). About 60 species of Anopheles mosquitoes act as malaria vectors by carrying the parasites; each endemic region features a particular population of vectors with their own dynamics (WHO 2007). The WHO provides guidance for national governments to combat malaria via control or elimination programs. Malaria control focuses on reducing mortality from the disease while elimination means preventing local transmission to humans by mosquitos, even if the disease vectors persist in the environment. The WHO recommends a broad suite of public health activities that contribute to malaria control and eventual elimination, including providing access to medication and treatment, using quality laboratory testing to diagnose malaria cases, monitoring for signs of drug resistance, providing mosquito nets or sprays to reduce transmission, monitoring the behaviour of mosquito vectors, reducing mosquito habitat, monitoring the movement of people across borders and maintaining high quality case records that are coordinated across agencies and countries (WHO 2007). In a case study on Turkmenistan, the WHO provides an example of a country that achieved malaria elimination via a combination of case management, monitoring the environmental factors that increase malaria risk, controlling the mosquito vector, educating the public, coordinating across agencies and cooperating with neighbouring countries (WHO 2012).

There are over 97 countries in which malaria is endemic, meaning "there is an ongoing, measurable incidence of cases and mosquito-borne transmission in an area over a succession of years." (WHO 2014c) Among malaria endemic countries, there are a variety of categories which lead to different priorities for malaria control efforts. Some countries have seasons and geographic zones with increased risk for malaria, whereas other countries have high risk for malaria all year throughout the territory. In high transmission countries such as Benin or Burkina Faso where malaria occurs nationwide, the entire population is living in an area where transmission is common. In these situations, the public health efforts focus on reducing mortality and transmission by providing care broadly and targeting the mosquito vector. Meanwhile, in low transmission countries malaria is limited to certain geographic areas. For example, in Botswana about $18 \%$ of the population lives in high transmission areas, but the remaining population is in low transmission areas. (WHO 2014c) In this situation public health officials may focus on methods to improve vector control, closely track malaria cases to determine their source and potentially work toward eliminating the disease in some regions (WHO 2007). The World Health Organization encourages countries to move through progressive stages of combating malaria - from control to elimination to prevention of re-introduction of the disease (WHO 2007). Although the WHO provides guidance, each country must choose its national priorities for malaria management based on their specific needs.

Management of the mosquito vector is a major activity among malaria control and elimination efforts. Primary tools employed for vector control are Indoor Residual Spraying (IRS), providing people with Long-Lasting Insecticidal Nets (LLIN), employing natural predators of the vectors such as fish that eat mosquito larvae, and reducing mosquito habitat (WHO 2007). Some of these activities are performed infrequently, such as annual spraying campaigns, while other vector control methods are on-going, such as distributing LLINs or managing water sources that could shelter mosquitos. When used correctly for the specific environment, these approaches can 
severely hinder the spread of malaria. While these methods of reducing malaria transmission have been shown to be effective, some high transmission endemic nations do not have the resources to field these measures on a universal scale. Furthermore, many malaria-endemic countries have limited capacity for disease surveillance and case management programs; they are not likely to have these programs in the near future (Lewis 2013). Meanwhile, low transmission countries need the information to identify which locations and seasons are most important to perform vector control activities in order to move toward elimination. Both high and low transmission countries could benefit from a system that helps them determine which areas of their country are at the highest risk for malaria transmission at a particular time. An estimate of the proliferation and behaviour of the mosquito vector is determined by the interaction of many environmental characteristics - including terrain type, soil moisture, and vegetation health. Understanding the state of these environmental variables helps predict the behaviour of mosquitos that carry malaria, however, in-situ measurements or observations of these characteristics are slow and costly. Infectious disease crosses political boundaries, thus countries need information about neighboring territories as well as their own jurisdiction. A method is needed that will provide public health officials with a method for monitoring malaria and forecasting areas with a high risk of transmission.

In response to these challenges, there are opportunities to increase the use of data derived from satellite-based remote sensing as an input to malaria control activities such as vector management and geographic analysis for case management. Satellites are already being utilized to support many other public service areas such as food security through the Famine Early Warning Systems Network (FEWS NET, http://www.fews.net/), disaster response through the International Charter: Space and Major Disasters (http://www.disasterscharter.org), and global climate initiatives through the Global Forest Observation Initiative (GFOI 2014). On a small scale, data from satellite remote sensing has been used in research projects to look for leading indicators of malaria and vector-borne diseases, however, this tool has yet to be implemented widely with operational tools that will help reduce the spread of vector-borne diseases.

\section{THE CONTRIBUTION OF SATELLITE DATA FOR MALARIA RISK MODELING}

This section provides examples of studies that have demonstrated the scientific principles underlying the use of satellite-based remote sensing data in support of modeling malaria risk. Such modeling efforts link concepts from several scientific disciplines, including entomology, environmental science, demography and epidemiology. The studies cited here confirm that it is feasible to build models predicting which geographic regions are most likely to need intervention at a particular time due to mosquito activity that could transmit malaria.

\section{Insert Table 1}

Models that estimate when and where risk of malaria transmission may increase are built on several types of information, addressing demography, public health, weather and terrain characteristics. Table 1 summarizes the core information needed to model malaria transmission risk; the table also shows potential sources where this information can be obtained. Demographic and public health data are important because more densely populated areas will have 
a higher transmission risk than sparsely populated areas. The disease may be transmitted to a greater or lesser extent depending on intrinsic characteristics of the population, including malaria resistance or other health conditions.

The environmental data regarding weather, terrain altitude and other terrain characteristics help predict the behaviour of the mosquitos that act as malaria vectors. Environmental characteristics such as ground temperatures and moisture affect mosquito populations and the incubation of P. falciparum (Rogers et al. 2002). These environmental variables can be efficiently measured from space using specialized instruments on satellites. The weather instruments operated by nations around the world such as microwave sounders, microwave imagers, infrared sounders and radars provide data about rainfall, surface temperature and humidity. Radar is also used to develop global maps of altitude called Digital Elevation Maps; the Shuttle Radar Topography mission record is a primary source for this data. Satellite instruments such as radiometers and visible imagers provide information about soil moisture, soil type and terrain cover. These satellite instruments passively receive light reflected from the earth's surface and filter the light to observe specific wavelengths. Every terrain type or surface feature viewed by a satellite will produce a particular signature when viewed through these filters, and an informative map can be created.

In order to develop a model that estimates which geographic regions have high risk for malaria transmission, environmental data is used to develop a hazard model that identifies where mosquitos carrying the malaria parasite are likely to be active. The demographic and public health data are used to develop a vulnerability model that identifies where populations are at risk of becoming ill if exposed to mosquitos carrying the malaria parasite. Information from these two models is combined to develop a risk model categorizes geographic locations on the basis of risk (Lopez-Rosado 2013). Based on such models, the local governments in endemic nations can allocate resources to help the areas with the highest risk of malaria transmission or governments can target their interventions to the specific sources of risk for a given area. Some geographic areas experience risk due to the arrival of people from high transmission areas, whereas other areas experience risk of malaria transmission due to the large number of mosquito habitats. For each situation, understanding the risk factors allows decision makers to determine the combination of vector control, population education, immigration management, case management and treatment that is best suited to the particular time and place.

Past studies have demonstrated the feasibility of satellite-enabled models of malaria transmission testing the premise that there is complex but strong correlation between environmental parameters and high rates of malaria transmission (Adimi et al. 2010). According to one study, 59\% of epidemiological studies that were analyzed of parasitic diseases and 16\% of malaria studies that were analyzed utilized remote sensing (Stefani et al. 2011).

One example is a study that estimated the level of mosquito activity in the Nouna District of Burkina Faso in 2008. This is one step toward building a hazard map, although it does not account for population vulnerability so it is not a complete risk analysis. The study applies data from an imager on the SPOT-5 satellite and considers an area measuring 60 by 60 kilometers. The resolution of the satellite imagery is 2.5 meters per pixel, and the area is observed through red, green, and near-infrared bands. The study uses 45 ground truth points to confirm the identification of different types of terrain on the satellite images. Even though this particular region has little epidemiological data, the various terrain types can still be classified by relative risk of Anopheles presence as derived from previous literature (Dambach et al. 2009). The study demonstrates the effectiveness of satellite imagery for classifying terrain according to likelihood of mosquito activity. Other studies demonstrate these methods in parts 
of Zambia (Clennon et al. 2010), using data from the Shuttle Radar Topography Mission (SRTM) and the Advanced Spaceborne Thermal Emission and Reflection Radiometer (ASTER) instrument. Another study examined data about Mexico (Pope, et al 1994) as part of a test program called Biospheric Monitoring and Disease Prediction (Di-Mod). This NASA project sought to "find associations between the life history of vector borne disease and environmental variables." The program obtains land cover data provided by Lansdsat Thematic Mapper (TM) satellite imagery. Landscape information and demographic data can then be correlated to determine what populations live in close proximity to potential vector breeding grounds (Curry et al. 2000).

There has been research on using environmental data from operational satellites to forecast months in advance where malaria risk will be high. Much of the data from these operational satellites is provided at no cost or minimal cost by government satellite owners. One cases study considers Tripura, India. In this study, nine years of vegetation health $(\mathrm{VH})$ indexes are compared against malaria outbreaks in the same region. The vegetation health indexes are derived from the Advanced Very High Resolution Radiometer (AVHRR) flown on a United States National Oceanic and Atmospheric Administration (NOAA) polar orbiting spacecraft. When this data is correlated with malaria transmission data for the same time period, the study reveals a close correlation between the temperature condition index (TCI), one of the VH indexes, and malaria cases. The study suggests that temperature condition index may be a three month leading indicator for where a malaria outbreak will occur (Kogan 2013). Two months of lead time may allow public health officials to define a plan for malaria control that potentially includes spraying campaigns, distribution of mosquito nets, deployment of fish that eat mosquito larvae, active case detection by health workers interviewing community members and coordination across public and private organizations.

The Centre National d'Etudes Spatiales (CNES, the national space agency of France) has worked on applying satellite-based models to tele-epidemiology in response to vector borne diseases. The CNES team uses data from the SPOT-5 satellite to create a predictive risk map for Rift Valley Fever, Dengue fever and other mosquito-borne diseases. This is a broad program focusing on multiple diseases in multiple countries: Malaria in urban areas of Argentina, Senegal, Mali, and Chad, and in rural areas of Burkina Faso, Bilharzia in China, Vibrio in the Mediterranean basin, and Dengue fever in Argentina and Martinique (CNES 2011). One specific application was in the Ferlo region of Senegal, where Rift Valley Fever is a significant economic factor both in its ability to infect humans and in the damage it does to the local livestock industry (Lafaye et al.). Remotely sensed data was again used to model ecological conditions such as rainfall, temperature, and vegetation cover. These parameters are used to estimate the presence of Aedes and Culex mosquitoes near livestock populations within a $15 \mathrm{~km} \mathrm{x} 15 \mathrm{~km}$ area. The study monitored the movements and parking locations of livestock herds and the dynamics of 1,350 ponds in the region. This effort began in 2003, with several measuring campaigns done in the rainy season (June-September) of 2010. The study found that a strategy of seasonal distribution of bed-nets, vaccinations, and larvicide application was feasible. The researchers were also able to create effective ZPOM maps (Zones Potentially Occupied by Mosquitoes).

Table 2 gives the technical specifications of several satellite instruments that generate data used in studies on risk for malaria or other vector-borne disease. Most of the instruments fly on satellites in sun-synchronous, polar orbits; this is a popular orbit for earth observation satellites because it allows satellites to regularly pass a particular location at the same time of day with similar lighting conditions. Many of the instruments are referenced in the discussion 
below; they include commercial and government-owned satellite projects that already generate data relevant to malaria risk modeling. The data sharing policies of the satellite owners are discussed more below. The table includes both passive and active instruments. Passive instruments, such as the imagers on SPOT-5, IKONOS and GeoEye-1, receive energy reflected from the earth. In contrast, active instruments such as the Shuttle Radar Topography Mission, generate an energy signal, send it to earth and receive the reflection. The characteristics of the reflection provide information about the earth. One parameter described for each instrument is the spectral range; this determines the specific wavelengths in which the instrument collects light. These wavelengths define which applications each instrument provides. None of the instruments listed in Table 2 are designed uniquely for monitoring environmental factors that influence health, but they provide data related to this topic and to many other topics. Most earth observation satellites provide data that supports many applications, thus it is not necessary to design a satellite specifically for monitoring malaria transmission risk. The questions to be considered for future satellite design are whether the update rate and precision of the information meet the needs of decision makers in malaria initiatives.

The table provides several insights into the existing data that is available for inclusion in malaria risk modeling. The revisit time, which determines the update rate, is provided for each instrument; this factor is dependent upon the instrument swath width - the diameter of the area the instrument can view on the ground - and the orbital parameters such as altitude and inclination relative to the equator. The instruments have revisit times from 2 to 16 days, except for the Shuttle Radar Topography Mission which collected data in a single campaign. The revisit time determines how often satellite-based data can be refreshed for use in a model. To consider the utility of satellite-based data, one must consider how often data users are capable of incorporating new data into their modeling efforts and decision making cycles. There is a tradeoff between the revisit time and ground spatial resolution. Instruments with larger swath widths and low resolution, such as VIIRS, provide updated information frequently but it is with low levels of detail. Instruments with narrow swath widths and high resolution such as the imagers on SPOT-5, IKONOS and GeoEye-1, provide information less frequently but give more detailed data. It may be helpful for long range forecasts to use lower resolution data to identify expected regions with high risk of malaria transmission; short term planning may be better informed by high resolution data that only targets geographic regions expected to have high risk.

\section{Insert Table 2}

\section{BARRIERS AND OPPORTUNITIES IN APPLYING SATELLITE REMOTE SENSING FOR MALARIA $\underline{\text { RISK MODELING }}$}

Data from satellites has primarily been used in small, proof-of-concept studies to track anopheline mosquito vectors in limited regions. For this method to be implemented on a wide scale, the tools must be operationalized to be easily adopted and regularly applied by decision makers that implement malaria control initiatives. For some high transmission, malaria-endemic countries, national scale surveys of the environmental risk factors will need to be conducted over all malaria-endemic regions at regular intervals.

The implementation of a large-scale program to apply satellite data to malaria transmission control may be broken down into three stages: 1) gathering data (from satellites and other sources); 2) creating and using a model to 
analyze the data and forecast geographic areas of high transmission risk; and, 3) responding to the forecasts by focusing preventative measures within high transmission risk areas. This section considers each of these stages, discussing possibilities, the progress that has been made and shortcomings that remain to be addressed.

\section{A. Accessing Environmental Satellite Data}

As previously discussed, remote sensing satellites can provide much of the environmental data needed for a system that forecasts malaria transmission risk. For the best results, the data for a given region should be updated regularly. Data from past years should also be maintained for comparison as a baseline. Past data can be useful for seeing historical trends in malaria under various environmental conditions. One important implementation question is how model users gain access to the data they need to implement this concept. Three potential sources of satellite earth observation data each have different economic models, policy conditions and data access rules. The three sources include commercial satellites, satellites owned by governments of nations where malaria is not endemic, and satellites owned by endemic nations; each category is discussed further below.

\section{Commercial Satellites}

One source of data is from commercial satellites whose operators produce images on request or deliver archived imagers from a library at a market driven price. An example of this is the SPOT (Système Pour l'Observation de la Terre) satellite system, operated by Airbus Defence and Space. According to their website, "SPOT products provide global, multidate, current geospatial information at local to nationwide scales from $0.3 €$ per sq. km." The satellites, one of which was used in the 2008 study in Burkina Faso, have a resolution of between 20 and 1.5 meters, and a 60 kilometer swath width (Astrium 2013). Another commercial source of satellite data is Digital Globe. The Digital Globe archives and their recently generated images are provided by a constellation of satellites including IKONOS, with panchromatic 0.80 meters and multispectral 3.2 meter resolutions, and GeoEye-1, with a $0.46 \mathrm{~m}$ panchromatic and $1.84 \mathrm{~m}$ multispectral resolution. The revisit time of these satellites is roughly three days (Digital Globe 2013). These are just a few examples commercial satellite earth observation companies; new start-up companies are emerging that plan to operate fleets of small satellites for earth imaging. Some commercially obtained data has high spatial resolution which can be quite costly and may not be necessary for a malaria risk model. A malaria early warning system will likely consider broad areas of land and benefit more from medium spatial resolution imagery.

\section{Government Satellites from Non-Endemic Nations}

Other sources of data are satellites owned by governments where malaria is not endemic, such as the United States. One source is the long-running Landsat program, managed jointly by the US Geological Survey (USGS) and NASA. Their latest platform, known as the Landsat Data Continuity Mission (LDCM) or Landsat 8 can sense blue, green, and red light in the visible spectrum, as well as near-infrared, mid-infrared, and thermal-infrared light. It offers repeat coverage approximately every 16 days, with a pixel size of 30 meters (USGS 2013). The USGS website provides free access to images taken by previous Landsat missions. The 1994 Mexico study by Pope et al. successfully uses data provided by the Landsat Thematic Mapper (TM) in seven spectral bands to classify land cover types.

A basic terrain altitude map may be obtained essentially for free from the 2000 Shuttle Radar Topography Mission (SRTM). The purpose of this mission was to accurately map the Earth's landmass between latitudes 60 degrees north and 56 degrees south, including areas that had previously been largely unmapped due to inaccessibility 
(Esler 2005). Using synthetic aperture radar, the mission obtained images with a worldwide resolution of three arc seconds (90 m) (Farr et al. 2007). The disadvantage of the SRTM is that the data is not real-time, not having been updated since the year 2000; the data is still useful, however, since elevation is generally a slowly changing variable. The digital elevation data produced by this mission was used in the 2010 malaria study by Clennon et al.

Still another source of data about land surface characteristics and climate variables is the Advanced Spaceborne Thermal Emission and Reflection Radiometer (ASTER). Launched by NASA in 1999, this platform has the advantage of a higher resolution $(15 \mathrm{~m})$, although its disadvantages include poor data in areas with weather interference (Nikolakopoulos 2006); the study by Clennon et al. found it to be less effective than SRTM data for their application.

For data about weather, a key source is the series of polar orbiting weather satellites operated by NOAA in the United States, the European Organisation for the Exploitation of Meteorological Satellites (EUMETSAT) and other weather agencies. The Advanced Very High Resolution Radiometer, the Advanced TIROS Operational Vertical Sounder (ATOVS) suite, and the Microwave Humidity Sounder (MHS) are examples of sensors that provide important weather and climate information that will help forecast the environmental factors that impact mosquito behaviour for the short and medium term (NOAA 2014). These satellites are particularly useful in areas that do not have in-situ networks of weather monitoring equipment. Near real-time data with updates several times per day is made freely available through NOAA and EUMETSAT.

\section{Government Satellites from Endemic Nations}

A third source of data may be satellites owned and operated by malaria-endemic countries. Currently, many developing countries are investing in their own fledgling satellite programs. Several countries beginning their first forays into space technology have pursued a national satellite project. Low earth orbit (LEO) satellites carrying imagery payloads typically have a complexity and cost that is feasible for new space nations. An example of this on the African continent is Nigeria which founded a national space agency since 1999, and started to operate their first nationally owned satellite in 2003 (Wood et al. 2012). Later, Nigeria developed NigeriaSat-X in partnership with a foreign firm; this satellite can provide multi-spectral imagery in 22 meter resolution (ESA 2013) and is an example of efforts by a malaria-endemic nation toward learning to build and operate its own remote-sensing platform. Other African countries that have operated nationally owned satellites include Algeria, Morocco, Egypt, and South Africa.

Malaria-endemic nations may choose to purchase or build their own satellites, depending on costs and resources. Some may choose to employ a combination of the two by building a satellite via collaboration with partners. An example of a collaborative satellite is Argentina's SAC-B satellite. Argentina built the bus domestically but several foreign partners contributed instruments. This approach gave the Argentine space program the chance to partner with and learn from more experienced space nations (Wood et al. 2012).

This third choice of a data source would undoubtedly be costlier in the short run when compared to the costs of purchasing or obtaining satellite imagery from platforms that are already in operation. As a short-term source, the data from well-established satellite operators like NASA, NOAA or EUMETSAT would be both an effective and economical option. It would require far less domestic investment for malaria-endemic nations. Nonetheless, there are potential long-run technological and economic benefits, discussed by Wood et al., to the development of a national 
satellite infrastructure. The source of data each malaria-endemic nation chooses to use will depend on each nation's access to resources and technology, as well as, their vision for the long term adoption of space technology.

\section{B. Analyzing the Data through a Model}

In Section II, we listed the different types of data that must be collected to forecast malaria risk. Once satellite data is gathered, it must be combined with other relevant data and analyzed with an effective model that can generate hazard maps, vulnerability maps and risk maps for malaria transmission. Some examples of simple malaria risk models have already been mentioned. For example, the Burkina Faso study discussed earlier relied primarily on satellite imagery combined with a ground survey to predict malaria activity levels for different terrains. The study accounted for data on elevation, rainfall, soil type, and vegetation indices. Generally, the small scale studies using remote sensing to track disease vectors have developed their own models for determining risk. For example, a 2004 study in Ethiopia using primarily climate data obtained through local weather stations was able to create an early warning model (Teklehaimanot et al. 2004).

Current efforts are developing more comprehensive models that take in data from a variety of sources and estimate risk of future malaria transmission. With such models public health officials in malaria-endemic nations may be able to deploy preventative measures like IRS and LLIN only to targeted areas that are expected to have high risk at a particular time; officials can also define how other interventions such as active case detection and population education can best be used. The goal is to use the model as a forecasting tool, so action can be taken to prevent a malaria outbreak rather than to simply respond to one (Lewis 2013). Multiple models have already been developed. Some have remotely sensed data as the most significant input factor, while others consider a wide variety of social and demographic factors as well.

Models are currently being developed that harness data such as the items listed in Table 1. Developers of such models aim to gradually increase the level of accuracy and extend the forecasting time. An example currently being developed at the Johns Hopkins University Applied Physics Laboratory is PRISM (Predicting Infectious Disease Scalable Model). This model makes use of many types of data about a geographic area and uses Fuzzy Association Rule Mining to identify areas of high and low risk. Although initially this model was intended to predict Dengue fever outbreaks, it may be extensible to monitor other infectious diseases (Buczak et al. 2012). This model has been tested in Peru; researchers gathered data on past dengue incidence rates, temperature and rainfall data (from the Tropical Rainfall Measuring Mission (TRMM)), as well as remotely sensed leaf area information using indices such as the Normalized Difference Vegetation Index (NDVI) and the Enhanced Vegetation Index (EVI). In addition, socio-economic data was taken as another predictor; this includes factors like sanitation and political stability. This data was then used to extrapolate fuzzy association rules of the form "if (X is $A) \rightarrow(Y$ is $B)$ ". Thus, if a variety of factors in an area like high rainfall, high past incidence rate, poor sanitation, and high temperatures correlate, it is likely to be an outbreak location (Buczak et al. 2012). Key in this approach is satellite-obtained information, which provided rainfall and leaf area data.

Another robust model is being developed by the Armed Forces Health Surveillance Center, Division of Global Emerging Infections Surveillance and Response System Operations (AFHSC-GEIS). This model uses three predictive factors to create advisories on disease outbreaks. These factors are (1) ecology and climate variables from 
satellite remote sensing data, (2) surveillance of human activity, and (3) animal-host surveillance for detecting vector and pathogen exposure events. A fourth measure, human-disease surveillance, is used as feedback for the program. The model was originally geared towards Rift Valley Fever prediction; "to date, this model has successfully predicted outbreaks of Rift Valley fever in Kenya, Tanzania, Somalia, Sudan, Madagascar and South Africa from 2006 through 2008." It is currently being used by the World Health Organization in those regions to prepare for outbreaks, and is being expanded to track other vector-borne diseases, such as malaria (Witt et al 2011). As a final example, data from MODIS and Landsat are being used to correlate environmental factors with malaria outbreaks in Ethiopia (Reid 2013).

The study by Pope et al. mentioned above was a component of a broad effort by NASA called Global Monitoring and Human Health (GMHH), a program started in 1985. The purpose of this effort was to explore how remote sensing and geographic information system (RS/GIS) can be applied to malaria surveillance. Phase I of the project focused on mosquito dynamics in Californian rice fields, while Phase II focused on southern Chiapas Mexico, in collaboration with universities and health agencies.

The above examples describe models that focus on satellite data. Other examples place an emphasis on other data sets, which are used to predict the vulnerability of the human population and the likelihood of pathogenhuman contact, in addition to simply considering the presence of the vector. One example is the RAID program (Risk Awareness Framework for Infectious Disease), the goal of which is to create predictive algorithms to determine the risk of transmission of malaria in a given location, and the time needed to take preventative measures. The program's efforts focused specifically on the risk that members of the military come in contact with a disease vector upon arrival in a new region. Using a combination of data on historical weather patterns, data regarding human activity, and data on the Anopheles mosquito populations, RAID attempted to determine if a location passed the environmental threshold for transmission (ETT). Vector dynamics and real-time meteorological data are combined to determine the number of virulent biting opportunities (VBO). The ETT and VBO are combined for each $5 \mathrm{~km}$ square geographic cell to calculate the risk of a susceptible person contracting malaria. This program has been tested on several case studies on a small scale, and has yet to be implemented on a larger scale (McKnight, 2014).

A recent study in the Republic of Tanzania was also successful in creating a hazard map for malaria, based on the probability of interaction with the hazard and the vulnerability of the exposed population. Tanzania in an endemic country with over $70 \%$ of the population living in high transmission areas (WHO 2014c). The model includes twenty socioeconomic, demographic, environmental, and governance-related vulnerability indicators, as well as one hazard indicator. The data included a significant amount of demographic information from the 20112012 HIV/AIDS and Malaria Indicator Survey (THMIS), such as individuals' housing conditions, occupations, levels of education, and age. The study used satellite data including a 2009 ESA GlobCover land classification map (Hagenlocher et al, 2015). The researchers created a model based on these twenty-one factors that showed a heterogeneous level of risk across Tanzania, with most high-risk areas concentrated in the south eastern part of the country. "Important factors contributing to modeled vulnerability patterns included proximity to agricultural fields and water bodies, housing conditions, child malnutrition/stunting, and low education, among others."

Another recent study in the Amhara regions of Ethiopia used combined date from SRTM and Landsat to create an extensive terrain map that showed high accuracy ( 93\%) when compared to ground truth points. It was 
found that terrain classified as wetland had a strong positive correlation with malaria cases (Midekisa et al, 2014). Another study has identified Google Earth imagery (which harnesses data from commercial and government satellite owners such as those listed above) as an inexpensive alternative to the use of a demographic surveillance system for the creation of a sampling frame to investigate malaria transmission. This demonstrates the affordability of a rudimentary risk map (Escamilla et al, 2014).

The number and variety of models that are being developed show that the technology for the predictive tracking of malaria transmission maturing. The progression of a long term research initiative such as the GMHH program mentioned above shows that the capabilities of these models have matured significantly over time, from the small-scale use of remotely sensed data in Californian rice fields to the application of these models to scores of villages in Chiapas, Mexico (Wood et al., 1991; Beck at al., 1997). The primary challenge for the future in creating a malaria early warning system, is in the implementation and routine operation by decision makers in malaria-endemic countries.

\section{Responding to the Data}

To effectively use all of the information provided by satellite-based and terrestrial sources, malaria-endemic countries implement a well-organized system that can receive the findings generated by models and respond with decisions about which interventions will reduce the impact of potential disease outbreaks. This section will summarize the World Health Organization's concept of an early warning system and how remote sensing data can be integrated into it.

According to the World Health Organization, the ideal framework for model driving an effective Malaria Early Warning System (MEWS) includes the following: (1) Vulnerability indicators (e.g. low herd immunity, widespread HIV, malnutrition and drug resistance), which will help predict the severity of an impact if the population is exposed to malaria; (2) transmission risk indicators based on vector activity (e.g. an unusual increase in rainfall or temperature); and (3) early case detection indicators from health facilities (e.g. malaria morbidity data using crucial epidemic thresholds) which can confirm an outbreak. Several countries have attempted to implement Malaria Early Warning Systems based on indicators such as excessive rainfall, however, many of these have had limited effectiveness due to poor collaboration between the health sector and other sectors, such as agriculture (WHO, 2001). For all of the data mentioned in previous sections to be used effectively, local governments must ensure that it is gathered and shared. This includes past epidemiological data to address vulnerability, environmental data to understand transmission dynamics, and current data from local health centers to enable early case detection. Malaria prevention programs must involve more than just the health sector, as many other sectors are affected, and many have significant data to contribute.

Once areas with the highest risk for transmission have been determined, local governments must respond to the data. National and local health officers can ensure the timely preparation and distribution of drugs, equipment, public education, training of health workers, and vector control tools like IRS and LLINs (WHO 2007).

\section{Malaria Early Warning System Architectural Framework}

\section{A. Systems Architecture Framework}


Satellite-based remote sensing data can be a valuable tool for malaria control if it is integrated into a broader system that allows the data to information decision makers as they design interventions for malaria control. As mentioned in the previous section, an effective Malaria Early Warning System will involve coordination among different levels of government, health facilities, scientists, health care providers, and the local population. This section provides an analysis of the implementation challenges of a MEWS harnessing satellite remote sensing data. The analysis uses a Systems Architecture approach, which is a product of Systems Engineering methods developed in the defence and aerospace industries to help solve complex engineering problems (Maier 2000). A basic framework of a Systems Architecture analysis is presented in Figure 1.

\section{Insert Figure 1}

The Systems Architecture Framework assumes that the system is occurring within a certain context that includes political, technical, organizational, and social factors. Within the Context, there exist Constraints and Opportunities that can either hinder or enhance the system's ability to meet its objectives. The System has a number of Stakeholders: individuals, organizations or groups, which express the Objectives of what the system should achieve to meet Stakeholder needs and provide valuable service. The Stakeholders allocate resources, or Forms, that work together to achieve the stated Objectives. The Forms, expressed as nouns, can be organizations, people, physical objects, virtual objects, programs and processes that execute Functions. Functions, expressed as verbs, transform the Forms in order to meet the Stakeholder Objectives. The Systems Architecture Framework seeks to identify which Forms will perform specific Functions in order to meet the Objectives.

\section{B. Systems Architecture for a MEWS}

Figure 2 shows an example of a Systems Architecture Framework applied to a generic Malaria Early Warning System that harnesses satellite data. This example of a MEWS framework provides a foundation from which Stakeholders can apply knowledge of their own Context to design a MEWS that meetings their local needs.

\section{Insert Figure 2}

Figure 2 shows that a MEWS will require coordination across many entities that may not work together on a regular basis. Many of the entities do not answer to the same authority and thus have no specific command or mandate to coordinate with each other, unless a mandate is provided by a central government authority. Input is needed from experts on insects, remote sensing, infectious diseases, weather, medicine and the needs of general public. The MEWS framework presented here assumes a Context that includes an effective public organizational structure, advanced science and engineering capabilities, and reliable healthcare personnel. If a malaria endemic nation is weak in some of these areas, they may need to seek support and capacity building from regional and international organizations. The individual entities and functions are further elucidated below so that a group implementing a MEWS using satellite data could adapt it to their specific needs.

Page 12 of 17 
The Objective of this Malaria Early Warning System is to provide public health officials with reliable, timely information that identifies areas at risk for malaria transmission. There are a series of Functions that must be executed to meet these objectives. These Functions and the corresponding sub-functions were identified in Section III and are further elaborated upon in Figure 3

\section{Insert Figure 3}

The list of functions and sub-functions in Figure 3 is quite extensive; it is likely that there is no individual entity would have the mandate to complete all of the tasks. There may be multiple entities or objects that are involved in each step of the system. The health information, environmental information, and census information are likely to be divided between multiple entities within a country or region. There may not be one organization that has the expertise to develop and maintain all of the models that would be necessary to evaluate the malaria transmission risk, especially if it harnesses advanced data processing methods for applying satellite data. Assuming this expertise already exists within a country or region, the system could harness this expertise to forecast malaria outbreaks. In order to effectively complete these tasks, the stakeholders must determine which Forms (i.e. organizations or programs) can complete each of these tasks based on their own system's context, constraints, and opportunities.

This analysis focuses on the assignment of Organizational Forms to Functions; thus we present the Malaria Early Warning System which harnesses satellite-based data with an organizationally-centric View. In Systems Architecture frameworks, a View is a representation of a system that emphasizes one system aspect. For this example MEWS, a set of organizations has been defined based on their scope of responsibilities within this system. These organizations will be the Forms of the system. The decision facing MEWS Stakeholders is to assign each Function to the Organizational Forms that can best carry it out. Figure 4 describes each Organizational Form according to which responsibilities they have within the country. This information provides a basis for deciding which Functions each Organizational Form can execute.

\section{Insert Figure 4}

The Organizational Forms are government ministries, government agencies, healthcare facilities, groups of experts, groups of health practitioners, and the local public. For this example, the Ministry of Health, based on its responsibility to protect the health of its citizens, will be the entity that leads the MEWS system. They will coordinate the effort and request support from each of the other Organizational Forms listed in Figure 4 in order to complete the system's Functions. There may be some natural links between the different organizations. For example, in some countries the Weather Service is under the Ministry of Environment; often the Regional and Local Health Officials report to the Ministry of Health. If there are not already coordination mechanisms in place, there may be a need for government action to create such mechanisms. The following discussion illustrates how Stakeholders in the system can assign the Functions to each Organizational Form according to the responsibilities listed in Figure 4. For a given malaria-endemic nation, the assignment of Functions is also based on local Opportunities and Constraints, such as funding limitations or levels of personnel experience. 
For the first Function, "Acquire and Manage Data," there are eight entities that are involved in this exemplary MEWS. The matrix in Table 3 shows these entities and proposes sub-functions to which they contribute.

\section{Insert Table 3}

For the activities within the first Function, the Ministry of Health would have the overall coordination role and they would be responsible for accessing the data from satellites and other sources. For example, the Ministry of Health would be responsible for applying the environmental or weather data from satellite earth observation, but they would link to the Ministry of Environment, the remote sensing agency, and the weather service to determine how to access, store and maintain that data. Likewise, the Ministry of Health would work with the census agency to apply demographic information that provides insight into population vulnerability. The Ministry of Health would be the responsible party for gathering and storing historical malaria data as well as tracking current malaria statistics. They would work together with the regional health facilities, doctors, nurses, and local population to gather the malaria data and track it. It may be helpful for the Ministry of Health to create an inter-agency team of professionals from the various entities that work together as a data management team to make sure that the coordination continues to operate smoothly.

In order to change the data from satellites and other sources into useful products for informed decision making, further expertise is needed from the Organizations. The entities involved in the second Function, "Develop ValueAdded Products," can be seen in Table 4.

\section{Insert Table 4}

For this Function, the Ministry of Health would rely on expertise within the other entities to derive the hazard model, vulnerability models and transmission risk models. The hazard model would be provided by the Ministry of Environment, the remote sensing agency, and the weather service because they are the entities within this example that have expertise about satellite remote sensing. These models may reference information from universities or science organizations that have knowledge about insect behavior and the relationship with environmental factors. These models identify the environmental characteristics that are conducive to malaria transmission. The Ministry of Health would work with the census agency to gain data that helps with assessing the vulnerability of the local population based on demographic and health statistics. In this example, the Ministry of Health combines these models to produce a transmission risk model and a forecast of the geographic areas expected to be most vulnerable to malaria.

When the forecast has been issued and potential malaria outbreak areas have been identified, a response to the threat can be organized. The entities involved in this Function, "Respond to Threat," are listed in Table 5.

\section{Insert Table 5}

"Responding to the Threat" means defining and executing a number of interventions. Some of the interventions recommended by the WHO are described in earlier sections. These interventions require coordination with a variety 
of entities, including high-level government ministries, local officials, municipals workers, emergency responders and the local population. In this example the Ministry of Health is be the leader and overall organizer, but they would need the services of other entities to effectively carry out a response. The Ministry of Defence and Emergency Responders can distribute supplies to high risk regions. The regional health facilities and local elected leaders work with the Ministry of Health to coordinate the local response. Doctors, nurses and public health workers educate the local population and seek out cases of malaria; the municipal workers distribute nets and spray insecticides in local jurisdictions. The local population would actively be engaged in this Function; they have the capability to reduce mosquito habitats by eliminating pools of water.

A team of responders from each organization involved in this function needs to be organized so that they could coordinate how this type of response would happen. Each party should have plans and procedures defined in advance so that the implementation of a response would be prompt and efficient. The Ministry of Health sponsors mock exercises and workshops that teach the various organizations what they need to do and how they can be prepared. This is another area that requires explicit decisions regarding allocation of funding and authority to enable training and procedures to be implemented. Such training is helpful for malaria as well as other vector-borne diseases.

The MEWS would be a complex system that coordinates activities amongst entities with different mandates. The Systems Architecture approach analyzes the complexity and shows how to assign activities to specific parts of the system. This ultimately provides a framework to set up such a system. While this particular example will not be appropriate for every situation, it provides a helpful foundation. The concepts for collaboration across public sector agencies in response to on-going health concerns apply to other challenges as well such as the Ebola epidemic. In order for satellite-based remote sensing data to have an impact on reducing malaria transmission, it must be incorporated in to a systemic intervention such as the MEWS described above.

\section{CONCLUSION}

This paper shows the current and potential roles of remote sensing in malaria prediction. The discussion considers past efforts to correlate environmental factors to malaria risk, summarizes a for an exemplary Malaria Early Warning System (MEWS), analyzes the data access policies for potential sources of satellite data, and describes the state-of the-art in modeling risk of malaria transmission.

There are detractors that question the fundamental premise of the logic presented in this paper. Some have argued that reducing vector-human contact may not be beneficial (Snow et al, 1995), (Trape, Rogier 1996). Some have argued that reducing malaria exposure would actually have a negative effect, because it lows acquisition of immunity (Smith et al. 2001). Nonetheless, the World Health Organization advocates vector control using measures like Indoor Residual Spraying (IRS) and Long-Lasting Insecticidal Nets (LLIN) as a primary method for the fight against this disease (WHO 2007).

A Malaria Early Warning system must incorporate many sources of data besides satellites, and models like PRISM are not solely based on remotely sensed data. There are many factors affecting malaria transmission that cannot be remotely measured. For example, intrinsic factors like host immunity often produce variations in disease patterns in the absence of environmental variation (Rogers et al. 2002). At the same time, satellites are key to ensuring the feasibility and cost-effectiveness of a Malaria Early Warning System because they provide regularly 
updated environmental information that cannot be easily accessed via terrestrial sources. Current and historical environmental data from satellites are fundamental to the creation of models that can forecast a potential malaria outbreak and provide time for a country or region to mitigate the threat. The Systems Architecture analysis of a Malaria Early Warning System shows that the success of such a system depends on a combination of technical innovation, scientific understanding and policies that enable effective coordination across public organizations. The technology will not ensure success of the initiative without supportive policies that define and fund clear roles for the relevant organizations. While satellite-based earth observation has great potential to contribute to reducing the impact of malaria, it must be adopted as part of a holistic, multi-disciplinary approach.

\section{ACKNOWLEDGEMENTS}

This research is supported by award \#1262260 from the Science of Science and Innovation Policy Program within the National Science Foundation. The authors appreciate the advice provided by Dr. William Breager and Brian Montgomery.

\section{REFERENCES}

1. Adimi, Farida, et al. "Towards Malaria Risk Prediction in Afghanistan Using Remote Sensing." Malaria Journal 9 (2010): 125-135. Print.

2. Astrium. Astrium, 2013. Web. 10 Aug. 2013. <http://www.astrium-geo.com/en/143-spot-satellite-imagery>.

3. Beck LR, Rodriguez MH, Dister SW, Rodriguez AD, Washino RK, Roberts DR, et al. Assessment of a remote sensing-based model for predicting malaria transmission risk in villages of Chiapas, Mexico. American Journal of Tropical Medicine and Hygiene. 1997; 56 (1): 99-106.

4. Buczak, Anna, et al. "A Data-Driven Epidemiological Prediction Method for Dengue Outbreaks Using Local and Remote Sensing Data." BioMed Central (2012): n. pag. Print.

5. Clennon, Julie, et al. "Identifying Malaria Vector Breeding Habitats with Remote Sensing Data and TerrainBased Landscape Indices in Zambia.” International Journal of Health Geographics (2010): n. pag. Print.

6. CNES (National Center for Space Studies), "Tele-epidemiology: satellites see mosquitoes coming. 2011 http://www.cnes.fr/web/CNES-en/9533-gp-tele-epidemiology-satellites-see-mosquitoes-coming.php Web.

7. Curry, Troy, and Jenn Small. Remote Sensing to Detect, Monitor and Predict Malaria Occurrence in Africa. N.p.: n.p., 2000. Print.

8. Dambach, Peter, et al. "Using High Spatial Resolution Remote Sensing for Risk Mapping of Malaria Occurrence in the Nouna District, Burkina Faso." Global Health Action 2 (2009): n. pag. Print.

9. Digital Globe. Digital Globe, 2013. Web. 12 Aug. 2013. <http://www.digitalglobe.com>.

10. European Space Agency, "EoPortal." 2013. Web. 12 Aug. 2013. <https://directory.eoportal.org>.

11. Escamilla V, Emch M, Dandalo L, Miller WC, Martinson F, Hoffman I. Sampling at community level by using satellite imagery and geographical analysis. Bulletin of the World Health Organization. 2014;92(9):690-4.

12. Esler, David. "Mapping the World in 3-D." Business and Commercial Aviation May 2005: 86-95. Print.

13. Farr, Tom, G. et al. "The Shuttle Radar Topography Mission." Reviews of Geophysics. 45:2 (2007). Print.

14. Global Forest Observations Initiative. July 2014. Web. 8. September. 2014. <http://www.gfoi.org/>.

15. Hagenlocher M, Castro MC. Mapping malaria risk and vulnerability in the United Republic of Tanzania: a spatial explicit model. Population Health Metrics. 2015;13.

16. IAMAT: International Association for Medical Assistance to Travellers, "World Malaria Risk Chart," July 2014. https://www.iamat.org/pdf/world_malaria_risk_chart.pdf Accessed January 27, 2014

17. Kogan, Felix., et al. "Modeling and Forecasting Malaria in Tripura, India using NOAA/AVHRR-Based Vegetation Health Indices." International Journal of Remote Sensing Applications. 3:2 (2013): 108-116. Print.

18. Lafaye, Murielle, et al. "Rift Valley Fever Dynamics in Senegal: A Project for Pro-Active Adaptation and Improvement of Livestock Raising Management." Geospatial Health 8.1 (2013). Print.

19. Lewis, Sheri. Telephone interview by Yaniv Kazansky. 25 July 2013.

20. Lopez-Rosado, Ramon. Personal interview. 12 Nov. 2012.

21. "Malaria." World Health Organization. World Health Organization, 2013. Web. 24 Jan. 2013. <http://www.who.int/topics/malaria/en/>.

22. Maier, Mark W., and Eberhardt Rechtin. The art of systems architecting. Vol. 2. Boca Raton: CRC press, 2000. 
23. McKnight, Darren. Interview. Integrity Applications, Inc. 2014.

24. Midekisa A, Senay GB, Wimberly MC. Multisensor earth observations to characterize wetlands and malaria epidemiology in Ethiopia. Water Resources Research. 2014;50(11):8791-806.

25. Najera. "Malaria Control: Achievements, Problems \& Strategies." World Health Organization (1999): n. pag. Print.

26. Nikolakopoulos, K. G., et al. "SRTM vs. ASTER Elevation Products, Comparison for Two Regions in Crete, Greece.” International Journal of Remote Sensing 27:21 (2006): 4819-4838. Print.

27. NOAA. 2014. Web. 7. September. 2014. <http://www.ospo.noaa.gov/Operations/POES/index.html>

28. Pope, Kevin, et al. "Remote Sensing of Tropical Wetlands for Malaria Control in Chiapas, Mexico." Ecological Applications 4:1 (1994): 81-90. Print.

29. Rogers, David J., et al. "Satellite Imagery in the Study and Forecast of Malaria." Nature 415 (2002): $710-715$. Print.

30. Smith, Tom, et al. "Child Mortality and Malaria Transmission Intensity in Africa." Trends in Parasitology 17:3 (2001): 145-149. Print.

31. Snow, Robert W., et al. "The Past, Present and Future of Childhood Malaria Mortality in Africa." Trends in Parasitology 17:12 (2001): 593-597. Print.

32. Snow, Robert W., Marsh, Kevin. "Will Reducing Plasmodium falciparum Transmission Alter Malaria Mortality Among African Children?” Parasitology Today 11:5 (1995): 188-190). Print.

33. Stefani, Aurelia, et al. "Studying Relationships between Environment and Malaria Incidence in Camopi (French Guiana) through the Objective Selection of Buffer-Based Landscape Characterisations." International Journal of Health Geographics (2011): n. pag. Print.

34. Teklehaimanot, Hailay D. et al. "Weather-Based Prediction of Plasmodium falciparum malaria in EpidemicProne Regions of Ethiopia II. Weather-based Prediction Systems Perform Comparably to Early Detection Systems in Identifying Times for Interventions." Malaria Journal 3:44 (2004): n. pag. Print.

35. Thomson, Madeleine C., Connor, Stephen J. "The Development of Malaria Early Warning Systems for Africa." Trends in Parasitology 17:9 (2001): 438-445. Print.

36. Trape, Jean-Francois, Rogier Christophe. "Combating Malaria Morbidity and Mortality by Reducing Transmission.” Parasitology Today 12 (1996): 236-240. Print.

37. USGS. U.S. Department of the Interior, 18 July 2013. Web. 11 Aug. 2013. <http://landsat.usgs.gov/LDCM_DataProduct.php>.

38. WHO, World Health Organization \& Global Partnership to Roll Back Malaria. "A Framework for Field Research in Africa Malaria Early Warning Systems: Concepts, Indicators and Partners." WHO Press, Geneva Switzerland, 2001. http://apps.who.int/iris/handle/10665/66848 Accessed June 6, 2015.

39. WHO, World Health Organization, "Malaria Elimination: A field manual for low and moderate endemic countries," WHO Press, Geneva, 2007. http://www.who.int/malaria/publications/atoz/9789241596084/en/ Accessed June 6, 2015.

40. WHO: World Health Organization. "Eliminating Malaria: Case Study 1. Achieving Elimination in Turkmenistan,” WHO Press, Geneva 2012. http://www.who.int/malaria/publications/atoz/9789241504300/en/ Accessed June 6, 2015.

41. (WHO 2014a) WHO: World Health Organization. March 2014. Web. 8 September. 2014. http://www.who.int/mediacentre/factsheets/fs094/en/

42. (WHO 2014b) WHO: World Health Organization, "Trends in Reported Malaria Incidence, 2000-2014," http://gamapserver.who.int/mapLibrary/Files/Maps/ProgressTowardsTragets final.jpg Accessed January 27 2014.

43. (WHO 2014c) WHO: World Health Organization. "World Malaria Report 2014. WHO Press, Geneva Switzerland, 2014. http://www.who.int/malaria/publications/world_malaria_report_2014/en Accessed June 6, 2015.

44. Wood BL, Beck LR, Washino RK, Palchick SM, Sebesta PD. SPECTRAL AND SPATIAL CHARACTERIZATION OF RICE FIELD MOSQUITO HABITAT. International Journal of Remote Sensing. 1991;12(3):621-6.

45. Wood, Danielle, and Annalisa Weigel. "Charting the Evolution of Satellite Programs in Developing CountriesThe Space Technology Ladder.” Space Policy (2012): n. pag. Print. 


\section{Table 1: Information Relevant to Modeling Malaria Risk for a Geographic Region}

\begin{tabular}{|c|c|c|}
\hline Information & Relevant Organizations & $\begin{array}{l}\text { Potential Data } \\
\text { Source }\end{array}$ \\
\hline $\begin{array}{l}\text { Demographic data showing } \\
\text { areas populated by humans }\end{array}$ & - National Census Agencies & - Census data records \\
\hline $\begin{array}{l}\text { Public Health data describing } \\
\text { past instances of malaria and } \\
\text { other factors such as age, } \\
\text { pregnancy and HIV status }\end{array}$ & - $\quad$ Public Health Agencies & $\begin{array}{ll}- & \text { Electronic Medical } \\
& \text { Record System }\end{array}$ \\
\hline $\begin{array}{l}\text { Weather Data (i.e. } \\
\text { temperature, humidity, } \\
\text { rainfall) }\end{array}$ & $\begin{array}{ll}- & \text { World Meteorological } \\
& \text { Organization } \\
\text { - } & \text { National Weather Agencies }\end{array}$ & $\begin{array}{ll}\text { - } & \text { Precipitation Radars } \\
\text { - } & \text { Microwave Sounders } \\
\text { - } & \text { Microwave Imagers } \\
\text { - } & \text { Infrared Sounders }\end{array}$ \\
\hline $\begin{array}{l}\text { Terrain Altitude (implies } \\
\text { potential locations for } \\
\text { standing water that allows } \\
\text { mosquitos to breed) }\end{array}$ & $\begin{array}{ll}- & \text { United States Geological } \\
& \text { Survey } \\
\text { - } & \text { National Survey and Mapping } \\
& \text { Agencies }\end{array}$ & $\begin{array}{l}\text { Digital Elevation } \\
\text { Maps (provided by } \\
\text { Shuttle Radar } \\
\text { Topography Mission, } \\
\text { among other } \\
\text { sources) } \\
\text { http://srtm.usgs.gov/i } \\
\text { ndex.php }\end{array}$ \\
\hline $\begin{array}{l}\text { Terrain Characteristics (i.e. } \\
\text { soil type, soil moisture and } \\
\text { vegetation cover) }\end{array}$ & $\begin{array}{l}\text { - } \quad \text { National Remote Sensing } \\
\text { Agencies } \\
\text { - } \quad \text { National Survey and Mapping } \\
\text { Agencies }\end{array}$ & $\begin{array}{ll}\text { - } & \text { Visible Imagers } \\
\text { - } & \text { Radiometers }\end{array}$ \\
\hline
\end{tabular}




\section{Table 2: Technical Specifications of Satellite Instruments that Produce Data Relevant to Malaria Risk Modeling}

\begin{tabular}{|c|c|c|c|c|c|c|}
\hline Instruments & Satellite & Application Areas & Spectral Range & $\begin{array}{c}\text { Orbit Revisit } \\
\text { Time }\end{array}$ & Swath Width & $\begin{array}{c}\text { Ground Spatial } \\
\text { Resolution }\end{array}$ \\
\hline Imager & SPOT-5 & $\begin{array}{l}\text { Mapping, urban and rural } \\
\text { planning, disaster } \\
\text { management }\end{array}$ & \begin{tabular}{|c|} 
Panchromatic (480- \\
710nm), Green (500- \\
590nm), Red (610- \\
680nm), Near Infrared \\
$(780-890 \mathrm{~nm})$
\end{tabular} & 2-3 days & $60 \mathrm{~km}$ & $\begin{array}{c}\text { Pan }(2.5-5 \mathrm{~m}), \\
\text { Multispectral }(10 \mathrm{~m}), \\
\text { Shortwave Infrared } \\
(20 \mathrm{~m})\end{array}$ \\
\hline $\begin{array}{c}\text { ASTER VNIR } \\
\text { Subsystem } \\
\end{array}$ & \multirow[b]{2}{*}{ Terra } & \multirow{2}{*}{$\begin{array}{c}\text { Land surface, climatology, } \\
\text { ecosystem dynamics, hazard } \\
\text { monitoring }\end{array}$} & \multirow{2}{*}{$\begin{array}{c}4 \text { bands, } 520 \text { to } 860 \\
n m\end{array}$} & \multirow[b]{2}{*}{ 4-16 days } & \multirow[b]{2}{*}{$60 \mathrm{~km}$} & \multirow[b]{2}{*}{$15 \mathrm{~m}$} \\
\hline \begin{tabular}{|c|}
$\begin{array}{c}\text { ASTER SWIR } \\
\text { Subsystem }\end{array}$ \\
ASTER TIR Subsystem \\
\end{tabular} & & & & & & \\
\hline Imager & IKONOS & High-resolution mapping & $\begin{array}{l}\text { panchromatic, } \\
\text { multispectral }\end{array}$ & $\sim 3$ days & $11.3 \mathrm{~km}$ & $\begin{array}{c}\text { panchromatic }(0.80 \\
\mathrm{m}), \text { multispectral } \\
(3.2 \mathrm{~m})\end{array}$ \\
\hline Imager & GeoEye-1 & High-resolution mapping & $\begin{array}{c}\text { panchromatic, blue } \\
(450-510 \mathrm{~nm}), \text { green } \\
(510-580 \mathrm{~nm}), \text { red } \\
(655-690 \mathrm{~nm}), \text { near-IR } \\
(780-920 \mathrm{~nm}) \\
\end{array}$ & 2-8 days & $15.2 \mathrm{~km}$ & $\begin{array}{c}\text { panchromatic- } 0.46 \\
\text { m multispectral- } \\
1.84 \mathrm{~m}\end{array}$ \\
\hline $\begin{array}{l}\text { Thermal Infrared } \\
\text { Sensor }\end{array}$ & \multirow{2}{*}{ Landsat 8} & $\begin{array}{c}\text { Land surface temperature } \\
\text { measurement }\end{array}$ & $\begin{array}{c}2 \text { bands, } \\
\mathrm{nm}\end{array}$ & \multirow{2}{*}{16 days } & \multirow{2}{*}{$185 \mathrm{~km}$} & $100 \mathrm{~m}$ \\
\hline $\begin{array}{l}\text { Operational Land } \\
\text { Imager }\end{array}$ & & Mapping & $\begin{array}{c}\text { NIR, SWIR, visible, } 9 \\
\text { bands }\end{array}$ & & & $\begin{array}{l}15 \mathrm{~m} \text { panchromatic, } \\
30 \mathrm{~m} \text { multispectral }\end{array}$ \\
\hline $\begin{array}{c}\text { Shuttle Radar } \\
\text { Topography Mission }\end{array}$ & $\begin{array}{c}\text { Space Shuttle } \\
\text { Endeavour }\end{array}$ & $\begin{array}{c}\text { Mapping, digital elevation } \\
\text { modeling }\end{array}$ & $\begin{array}{c}\text { Active Radar } \\
\text { instrument in C-band } \\
\text { and X-band } \\
\end{array}$ & $\begin{array}{c}11 \text { day mission in } \\
2000\end{array}$ & $225 \mathrm{~km}$ & $90 \mathrm{~m}$ and $30 \mathrm{~m}$ \\
\hline $\begin{array}{c}\text { Advanced Technology } \\
\text { Microwave Sounder }\end{array}$ & \multirow{3}{*}{$\begin{array}{l}\text { JPSS-1, } \\
\text { JPSS-2, } \\
\text { Suomi NPP }\end{array}$} & $\begin{array}{c}\text { Atmospheric temperature } \\
\text { and moisture for operational } \\
\text { weather }\end{array}$ & $\begin{array}{c}22 \text { bands from } 23 \mathrm{GHz} \\
\text { to } 183 \mathrm{GHz}\end{array}$ & \multirow{3}{*}{$\begin{array}{l}\text { Global coverage } \\
\text { twice a day }\end{array}$} & $2600 \mathrm{~km}$ & $15.8-74.8 \mathrm{~m}$ \\
\hline $\begin{array}{l}\text { Cross-track Infrared } \\
\text { Sounder }\end{array}$ & & $\begin{array}{l}\text { Profiling of atmospheric } \\
\text { humidity and temperature }\end{array}$ & $\begin{array}{c}1305 \text { spectral } \\
\text { channels from } 3920 \\
\mathrm{~nm} \text { to } 1538 \mathrm{~nm} \\
\end{array}$ & & $2200 \mathrm{~km}$ & $\begin{array}{c}14 \text { km diameter, } 1 \\
\text { km vertical layer }\end{array}$ \\
\hline $\begin{array}{c}\text { Visible Infrared Imaging } \\
\text { Radiometer Suite }\end{array}$ & & \begin{tabular}{|c|} 
Observations of clouds, soil \\
moisture, vegetation, surface \\
temperature, ocean color
\end{tabular} & $\begin{array}{c}22 \text { bands from } 412 \mathrm{~nm} \\
\text { to } 1200 \mathrm{~nm}\end{array}$ & & $3000 \mathrm{~km}$ & $400 \mathrm{~m}$ \\
\hline
\end{tabular}




\begin{tabular}{|l|c|c|c|c|c|}
\hline & \multicolumn{5}{|c|}{ Acquire and Manage Data } \\
\hline & $\begin{array}{c}\text { Access } \\
\text { Census, } \\
\text { Health Data }\end{array}$ & $\begin{array}{c}\text { Access } \\
\text { Weather, } \\
\text { Climate Data }\end{array}$ & $\begin{array}{c}\text { Access } \\
\text { Env. } \\
\text { Info }\end{array}$ & $\begin{array}{c}\text { Maintain } \\
\text { Malaria } \\
\text { Data }\end{array}$ & $\begin{array}{c}\text { Monitor } \\
\text { Malaria } \\
\text { Stats }\end{array}$ \\
\hline Ministry of Health & $\mathrm{X}$ & $\mathrm{X}$ & $\mathrm{X}$ & $\mathrm{X}$ & $\mathrm{X}$ \\
\hline $\begin{array}{l}\text { Ministry of } \\
\text { Environment }\end{array}$ & & $\mathrm{X}$ & $\mathrm{X}$ & & \\
\hline $\begin{array}{l}\text { Space/Remote } \\
\text { Sensing Agency }\end{array}$ & & $\mathrm{X}$ & & & \\
\hline Weather Service & & $\mathrm{X}$ & & & \\
\hline Census Agency & $\mathrm{X}$ & & & & \\
\hline $\begin{array}{l}\text { Regional/Local } \\
\text { Health Facilities }\end{array}$ & & & & & \\
\hline Doctors and Nurses & & & & & $\mathrm{X}$ \\
\hline Local Population & & & & & $\mathrm{X}$ \\
\hline
\end{tabular}

Table 3: Acquire and Manage Data 


\section{Develop Value-Added Products}

Forecas

\section{Derive Produce Run}

Hazard Vulnerabil Transmiss Outbrea

Model ity Model ion Model $\mathrm{k}$

\section{Ministry of Health} Ministry of

\section{Environment}

Space/Remote

Sensing Agency

Weather Service

Census Agency

\begin{tabular}{|c|c|}
\hline$X$ & $X$ \\
\hline
\end{tabular}

Table 4: Develop Value-Added Products 


\begin{tabular}{|l|c|c|c|c|c|c|}
\hline & \multicolumn{5}{|c|}{ Respond to Threat } \\
\hline & $\begin{array}{c}\text { Coordinate } \\
\text { Response }\end{array}$ & $\begin{array}{c}\text { Notify } \\
\text { Local } \\
\text { Leaders }\end{array}$ & $\begin{array}{c}\text { Move } \\
\text { Supplies }\end{array}$ & $\begin{array}{c}\text { Educate } \\
\text { Local } \\
\text { Population }\end{array}$ & $\begin{array}{c}\text { Spray } \\
\text { Insecticides }\end{array}$ & $\begin{array}{c}\text { Distribut } \\
\text { e Nets }\end{array}$ \\
\hline Ministry of Health & $\mathrm{X}$ & $\mathrm{X}$ & $\mathrm{X}$ & & & \\
\hline $\begin{array}{l}\text { Ministry of } \\
\text { Defense }\end{array}$ & & & $\mathrm{X}$ & & & \\
\hline $\begin{array}{l}\text { Regional/Local } \\
\text { Health Facilities }\end{array}$ & $\mathrm{X}$ & & & & & \\
\hline Elected Officials & $\mathrm{X}$ & & & & & \\
\hline $\begin{array}{l}\text { Doctors and } \\
\text { Nurses }\end{array}$ & & & & $\mathrm{X}$ & & \\
\hline $\begin{array}{l}\text { Municipal } \\
\text { Workers/ } \\
\text { Emergency } \\
\text { Responders }\end{array}$ & & & & & & \\
\hline Local Population & & & & & & \\
\hline
\end{tabular}


Constraints or Opportunities

\section{Context}

System Boundary

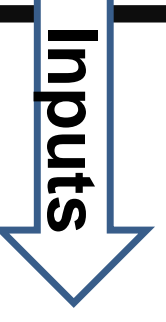

\section{System Stakeholders}

Individuals, organizations or groups that affect or are affected by the system; Primary stakeholders have direct decision making authority or system impact

Allocate

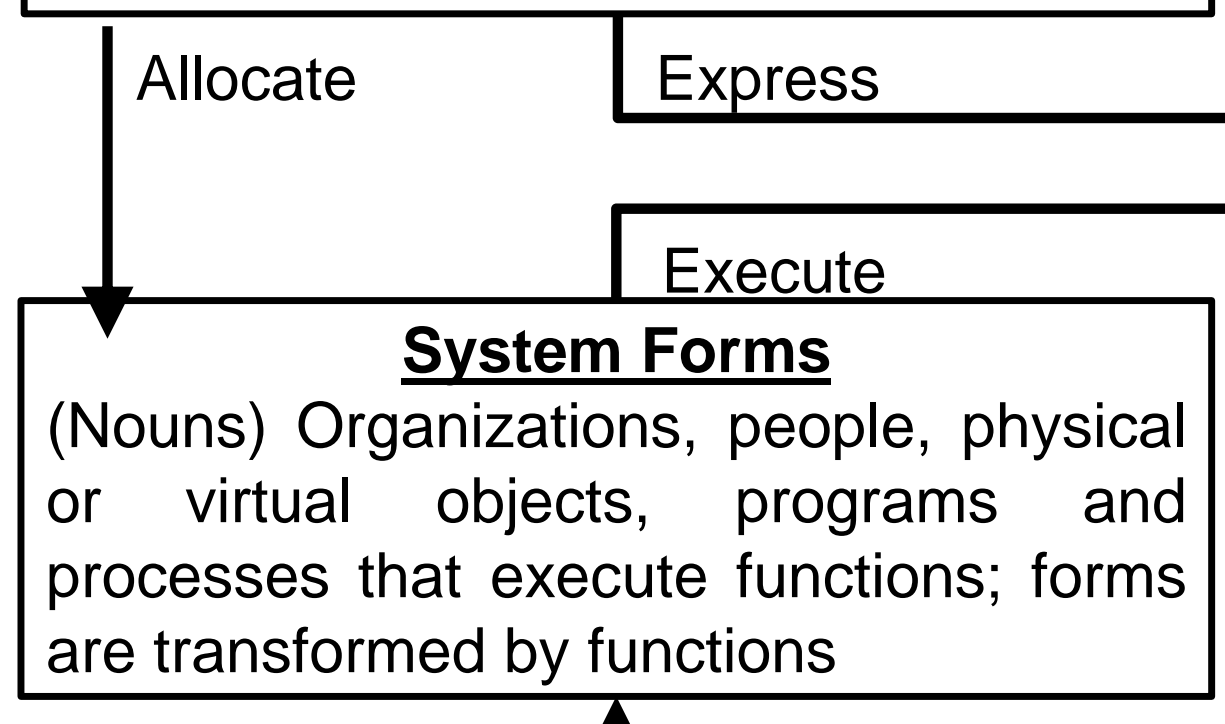

Emergent Properties

\section{Stakeholder Objectives} High level goals of the primary stakeholders that define what the system should achieve

Figure 1: Systems Architecture Framework developed by the authors to analyse complex, technology enabled public service systems 
Constraints or Opportunities

Context

\section{MEWS Boundary}

Emergent Properties

\section{MEWS Stakeholders}

Public Health Officials, Infectious Disease Experts, Remote Sensing Experts, Climate and Weather Scientists, Community Care Practitioners, General Public

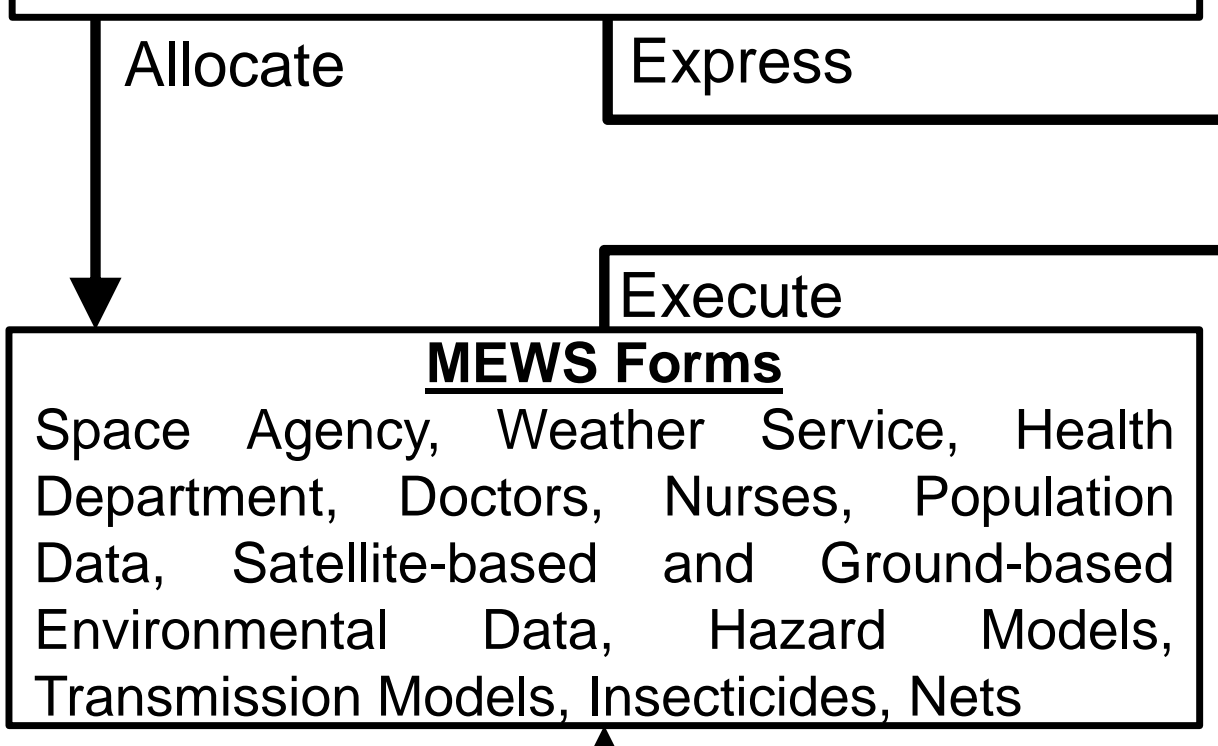

Stakeholder Objectives

Public health officials have reliable, timely information that identifies areas at risk for malaria transmission, allowing them to respond accordingly.

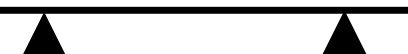

Meet

\section{MEWS Functions}

Acquire data, manage data, model, assess risk, forecast, disseminate, respond

Transform

Figure 2: MEWS Systems Architecture Framework 


\section{Acquire and Manage Data}

Develop ValueAdded Products
Respond to Threat
- Access census and health information

- Access weather and climate data from satellite, airborne and ground-based sensors

- Access

Environmental information from satellite, airborne and ground-based sensors

- Maintain historical malaria prevalence data

- Monitor current malaria statistics
- Derive hazard model from environmental and weather data

- Produce vulnerability model from census data and health information

- Run transmission model based on the life-cycle of malaria parasite and vector

- Forecast which regions will be most vulnerable to a malaria outbreak based on model above
- Treat malaria-infected patients

- Coordinate response

- Notify regional and local leaders

- Move supplies to local health facilities

- Educate local population

- Execute indoor residual spraying campaign

- Distribute bed nets

- Identify and document malaria cases

- Manage migration of people from high transmission areas 
Ministry of Health

\section{Ministry of Environment}

\section{Ministry of Defense}

\section{Space/Remote Sensing Agency}

\section{Weather Service}

Census Agency
- Responsible for providing basic human services and ultimately protecting the health of the citizens of that country. In this example, the MEWS would be housed inside the Ministry of Health.

- Responsible for monitoring and protecting the environment of a nation

- Responsible for defense of a nation, but also aids in national emergencies

- Responsible for operating satellites or providing access to satellite data that can help monitor weather and climate

- Responsible for producing weather forecasts and maintaining historical weather and climate information

- Responsible for collecting and cataloging demographic data about a country's population

- Responsible for coordinating health facilities on a regional level

- Responsible for providing medical treatment and information to the local populace

- Responsible for providing local government services and first responders to emergency situations

- Inhabitants of a country responsible for communicating disease outbreak information to regional and local leaders. Also responsible for carrying out suggested prevention methods.

Figure 4: This Systems Architecture Analysis of the Malaria Early Warning System focuses on the role of Organizations as Forms that execute Functions within Figure 5 